\title{
The Impact of Epstein Barr-Virus on Therapeutic Options of Lymphoma
}

\author{
Ahed J Alkhatib ${ }^{1,2 *}$, Marwa Yousry Mohamed $^{3}$ and Ghormallah Abdullah AlGhamdi ${ }^{4}$ \\ ${ }^{1}$ Department of Legal Medicine, Jordan University of Science and Technology, Jordan \\ ${ }^{2}$ Department of medicine and critical care, International Mariinskaya Academy, Jordan \\ ${ }^{3}$ Department of Biology, College of Science, Imam Mohammad Ibn Saud Islamic University, KSA \\ ${ }^{4}$ Ministry of health, Health- Affairs of Tabuk, KSA
}

*Corresponding author: Ahed J Alkhatib, Department of Legal Medicine, Jordan University of Science and Technology, Jordan, Tel: 00962795905145.

To Cite This Article: Ahed J Alkhatib, The Impact of Epstein Barr-Virus on Therapeutic Options of Lymphoma. 2020 - 8(1). AJBSR.MS.ID.001240. DOI: 10.34297/AJBSR.2020.08.001240.

Received: 㘹 March 01, 2020; Published: 眥 March 12, 2020

\begin{abstract}
Abstarct
This review study aimed to investigate the impacts of having Epstein Bar-Virus (EBV) positivity on therapeutic options of lymphomas. About one third of lymphomas are positive for EBV. Anyhow, existing therapeutic options are almost similar for treating lymphomas as either positive or negative for EBV. Future trends are thought to differ based on more better understanding of biology of EBV and to target such mechanisms that counteract or interfere with its pathogenesis including activation of apoptotic pathways or activating immunosuppression mechanisms.
\end{abstract}

Keywords: Lymphoma, EBV, Prevalence, Immunosuppression, Apoptosis, EBV biology

\section{Introduction}

It has been estimated that more than ninety percent of adult persons at global level have the potential of having latent EBV. Although latent EBV infection is likely to be highly occurred, but there is a low possibility to develop lymphoma associated with EBV [1].

EBV associated lymphomas are considered as a part of hematologic cancers that have in common latent EBV in tumor cells. Some endemic Burkitt lymphoma (BL) or HIV-associated lymphoma in central nervous system (CNS) are positive for EBV in almost all cases. Approximately one third of Hodgkin's Lymphoma (HL) are positive for EBV, while it is a rare condition to have positive EBV in Diffuse large B-cell lymphoma (DLBCL) [1-3]. Certain conditions associated with immune alterations may lead to increased proportions for developing EBV associated lymphoma. These conditions include having HIV, immunodeficiency related to congenital factors, and immunosuppression conditions following organ transplantation. post-transplant immunosuppression, or chronic active EBV [4-6].

The discovery of EBV is due to 1964 [3]. At that time, oncogenic viruses were not attracting the attention to be of clinical significance. Denis Burkitt's was the scientist who discovered this virus through determination of the most common tumour in childhood in Africa, while it was not known in the West [4]. It was not easy for scientific community to admit the relation between EBV and BL. This issue took several years to be accepted. It is worth to mention that sero-epidemiologic investigations showed that EBV was common among various human populations. Most people at global level are positive for EBV in form of asymptomatic infection [7,8]. It has been estimated that cancers due to viruses represent approximately $10 \%$ of cancer incidence at global level $[9,10]$.

EBV is known by its ability to induce infectious mononucleosis (IM). EBV has contributed to several a wide spectrum of malignant 
lesions including BL, hemophagocytic lymphohistiocytosis, HL, gastric cancer and nasopharyngeal carcinoma $[11,12]$.

\section{Therapeutic Options}

In the treatment of lymphomas associated with EBV, there are little therapeutic options that may lead to impact the virus within malignant cells. However, in the majority of cases, no differences in the therapeutic options have been identified according to the existence of EBV or not. Existing therapeutic approaches have made focus on interfering with biological aspects of EBV to target lymphomas associated with EBV as future therapeutic strategies. Thoughtfully, EBV-explicit methodologies incorporate reinforcing the antiviral/antitumor resistant reaction with antibodies or EBVexplicit cytotoxic T-lymphocytes, initiating lytic viral qualities to render the tumour cells helpless to antiviral treatments, and hindering the downstream prosurvival or antiapoptotic pathways that might be actuated by dormant EBV proteins. EBV-explicit cytotoxic T-cell imbuements have demonstrated viable in EBVrelated post transplantation lymphoproliferative disorder (EBVPTLD) and extending such assenting immunotherapies to other EBV-related malignancies is a place of dynamic research. In any case, other EBV-related lymphomas normally have progressively limited, less immunogenic varieties of viral antigens to restoratively focus with assenting immunotherapy contrasted and EBV-PTLD. Moreover, the threatening EBV-positive tumour cells of HL are dispersed in the midst of a thick penetrate of administrative T-cells, macrophages, and different cells that may hose the antitumor adequacy of supportive immunotherapy. Methodologies to beat these hindrances are regions of continuous preclinical and clinical examinations. Some rising ways to deal with EBV-related lymphomas incorporate the coupling of specialists that prompt lytic viral replication with antiherpesvirus operators, or the utilization of little particle inhibitors that square deteriorating pathways that are constitutively actuated by EBV. EBV antibodies appear to be generally encouraging for the treatment or counteractive action of EBV-related malignancies, as opposed to the avoidance of essential EBV contamination. EBV immunization preliminaries in patients with remaining or low-mass EBV-related malignancies or for the counteractive action of EBV-PTLD in EBV-seronegative patients anticipating strong organ transplantation are progressing [1].

In many occasions, the way to deal with EBV-positive lymphomas doesn't contrast from EBV-negative lymphomas of a similar histology [13]. The special cases are with regards to investigational conventions or where a receptive immunotherapy approach is accessible [14,15].

At the point when EBV-positive lymphomas emerge in the setting of immunosuppression, enhancing the invulnerable deformity can aid the treatment of these lymphomas [16,17]. In HIV-related lymphomas, antiretroviral treatment is commonly fitting albeit potential medication communications and the impacts of chemotherapy on the capacity to keep up HAART treatment as far as sickness, heaving and mucositis must be considered with respect to the planning of antiretroviral treatment $[5,18]$. In any case, for EBV-related lymphomas in HIV patients, commencement of antiretroviral treatment alone is lacking for treatment. This is rather than AIDS-related Kaposi sarcoma where inception of antiretroviral treatment is frequently a standard methodology in patients who are asymptomatic or insignificantly symptomatic and are antiretroviral innocent $[19,20]$. In EBV-PTLD, select cases may profit by decrease of immunosuppression as the sole mediation or as a component of the treatment plan $[3,21]$.

\section{Conclusion}

Therapeutic options for lymphomas associated with EBV are not greatly varied from those with negative lymphomas for EBV. However, existing therapeutic options include targeting biological aspects of EBV and may need future studies to be well established.

\section{References}

1. Kanakry JA, Ambinder RF (2013) EBV-related lymphomas: new approaches to treatment. Curr Treat Options Oncol 14(2): 224-236.

2. Levin LI, Chang ET, Ambinder RF, Lennette ET, Rubertone MV, et al. (2012) Atypical prediagnosis Epstein-Barr virus serology restricted to EBV-positive Hodgkin lymphoma. Blood 120(18): 3750-3755.

3. Shannon Lowe C, Rickinson A (2019) The Global Landscape of EBVAssociated Tumors. Front Oncol 9: p. 713.

4. Ambinder RF (2007) Epstein-Barr virus and hodgkin lymphoma. Hematol Am Soc Hematol Educ Program 204-209.

5. Biggar RJ, Jaffe ES, Goedert JJ, Chaturvedi A, Pfeiffer R, et al. (2006) Hodgkin lymphoma and immunodeficiency in persons with HIV/AIDS. Blood 108(12): 3786-3791.

6. Goedert JJ, Bower M (2012) Impact of highly effective antiretroviral therapy on the risk for Hodgkin lymphoma among people with human immunodeficiency virus infection. Curr Opin Oncol 24(5): 531-536.

7. Zur Hausen H, Schulte Holthausen H (1970) Presence of EB virus nucleic acid homology in a "virus-free" line of Burkitt tumour cells. Nature 227(5255): 245-248.

8. Epstein MA, Achong BG, Pope JH (1967) Virus in cultured lymphoblasts from a New Guinea Burkitt lymphoma. Br Med J 2(5547): 290-201.

9. Parkin DM (2006) The global health burden of infection-associated cancers in the year 2002. Int J Cancer 118(12): 3030-3044.

10. de Martel C, Ferlay J, Franceschi S, Vignat J, Bray F, et al (2012) Global burden of cancers attributable to infections in 2008: a review and synthetic analysis. Lancet Oncol 13(6): 607-615.

11. Sherif A Rezk, Xiaohu I Zhao, Lawrence M Weiss (2018) Epstein-Barr virus (EBV)-associated lymphoid proliferations, a 2018 update. Hum Pathol 79: 18-41.

12. Maeda E, Akahane M, Kiryu S, Kato N, Yoshikawa T, et al (2009) Spectrum of Epstein-Barr virus-related diseases: a pictorial review. Jpn J Radiol 27(1): 4-19.

13. Duran-Struuck R, Huang CA, Matar AJ (2019) Cellular Therapies for the Treatment of Hematological Malignancies; Swine Are an Ideal Preclinical Model. Front Oncol 21(9): p. 418.

14. He J, Tang XF, Chen QY, Mai HQ Huang ZF, et al. (2012) Ex vivo expansion of tumor-infiltrating lymphocytes from nasopharyngeal carcinoma patients for adoptive immunotherapy. Chin J Cancer 31(6): 287-294. 
15. Louis CU, Straathof K, Bollard CM, Gerken C, Huls MH, et al. (2009) Enhancing the in vivo expansion of adoptively transferred EBV-specific CTL with lymphodepleting CD45 monoclonal antibodies in NPC patients. Blood 113(11): 2442-2450.

16. Morscio J, Finalet Ferreiro J, Vander Borght S, Bittoun E, Gheysens O, et al. (2017) Identification of distinct subgroups of EBV-positive posttransplant diffuse large B-cell lymphoma. Mod Pathol 30(3): 370-381.

17. Dharnidharka VR, Webster AC, Martinez OM, Preiksaitis JK, Leblond V, et al. (2016) Post-transplant lymphoproliferative disorders. Nat Rev Dis Primers 2: Pp. 15088.

18. Carbone A, Cesarman E, Spina M, Gloghini A, Schulz TF, et al. (2009) HIVassociated lymphomas and gamma-herpesviruses. Blood 113(6): 12131224
19. Bigi R, Landis JT, An H, Caro Vegas C, Raab Traub N, et al. (2018) EpsteinBarr virus enhances genome maintenance of Kaposi sarcoma-associated herpesvirus. Proc Natl Acad Sci U S A 115(48): E11379-E11387.

20. Moore PS, Chang Y (2010) Why do viruses cause cancer? Highlights of the first century of human tumour virology. Nat Rev Cancer 10(12): 878889.

21. Burkitt D (1958) A sarcoma involving the jaws in African children. Br J Surg 46(197): 218-223 